\title{
Methyl N-(6-Phenylsulfanyl-1h-Benzimidazol-2-Yl) Carbamate: A Non-Toxic Substitute of Colchicine for Quality Metaphase Chromosome Preparation from Normal and Tumor Cells for Cytogenetic Analysis
}

Ambica Baru, Nilambra Dogra and Tapas Mukhopadhyay*

National Centre for Human Genome Studies and Research, Panjab University, Chandigarh, India

"Corresponding author: Tapas Mukhopadhyay, National Centre for Human Genome Studies and Research, Panjab University, Chandigarh, India-160014, Tel: 91-172-2534118; Fax: +91-172-2534118; E-mail: tmukhopa@hotmail.com

Received date: July 04, 2016; Accepted date: July 27, 2016; Published date: August 04, 2016

Copyright: ( 2016 Baru A, et al. This is an open-access article distributed under the terms of the Creative Commons Attribution License, which permits unrestricted use, distribution, and reproduction in any medium, provided the original author and source are credited.

\section{Abstract}

Background: Methyl N-(6-phenylsulfanyl-1H-benzimidazol-2-yl) carbamate [Fenbendazole, FZ] is an anthelmintic drug which acts by selectively binding to $\beta$ tubulin of nematodes, inhibiting the tubulin polymerization and blocking microtubule dependent glucose uptake. The anti-proliferative effect of Fenbendazole is partly due to its ability to affect microtubule dynamics and arrest cells at a pro-metaphase state with an intact mitotic spindle.

Findings: Here, we show that Fenbendazole - a benzimidazole anthelmintic drug, can be used as an alternative to colchicine for making high quality chromosome preparations for karyotyping and further cytogenetic analysis. This drug could efficiently block the proliferation of human tumor cell lines as well as peripheral blood lymphocytes in culture by arresting them at G2M phase. FZ treatment at $1 \mathrm{uM}$ concentration for $3 \mathrm{~h}$ resulted in high mitotic indices resulting in a number of well spread metaphasic plates in suspension as well as adherent cultures. The morphology of metaphase chromosomes obtained from FZ treated samples was at par with those prepared from colchicine.

Conclusion: Altogether, our results show FZ as an extremely efficient, relatively non-toxic and inexpensive G2/M blocker which may be utilized as a suitable alternative of colchicine for routine cytogenetic analysis.

Keywords: Metaphase chromosomes; Mitotic agent; Karyotyping

\section{Introduction}

Microtubule targeting drugs have long been used for chromosome preparation. Colchicine and colcemid are well known compounds used extensively in cytogenetic laboratories. Cellular uptake and the binding of colchicine and colcemid to tubulin are well established [1]. Tjio and Levan first used colchicine for metaphase chromosome spreads [2]. Later, colchicine and a number of its analogues that interfere with microtubule dynamics were found to be useful for preparation of mitotic chromosomes for

Benzimidazoles represent a class of broad-spectrum anthelmintics. They also show activity against fungi and mammalian cells $[3,4]$. It is well established that benzimidazole compounds exert their therapeutic effects through binding to helminth $\beta$-tubulin, thus disrupting microtubule-based cellular processes [5]. Microtubules are composed of $\alpha-\beta$ tubulin dimers, and play important roles in various cellular functions including mitosis [6]. They exhibit differential dynamic behavior during different phases of the cell cycle. Inhibition of the microtubule assembly dynamics causes cell cycle arrest. In vitro studies using enriched extracts of helminthic and mammalian tubulin have suggested that tubulin is the primary molecular target of the benzimidazoles $[5,7,8]$.

Fenbendazole (FZ) is a broad-spectrum benzimidazole anthelminth approved for use in numerous animal species [9]. Recently we have shown that fenbendazole, a compound belonging to the benzimidazole group exhibits potent proteasomal inhibitory activity [10]. FZ affects microtubule dynamics and arrests cells at a pro-metaphase state with an intact mitotic spindle. This arrest is distinct from the one caused by colchicine, which results in complete depolymerization of tubulin network. Unlike colchicine, vinca alkaloids and taxanes, which are established inhibitors of cancer cell proliferation, fenbendazole acts in micromolar range and is considered to have limited toxicity.

Treatment of slow growing tumor cells with colcemid/colchicine often leads to the severe shortening of the chromosome architecture due to enhanced compaction which often interferes with cytogenetic analysis. Here, we report the identification of a novel antimitotic compound that can be successfully used for making high-quality metaphase spreads from human peripheral blood samples, tumor cell lines and primary cultures. FZ can serve as an efficient, inexpensive and less toxic substitute of colchicine for cytogenetic analysis.

\section{Materials and Methods}

\section{Cell culture}

Human non-small cell lung cancer cell lines H460 and A549, colon cancer cell line HCT116 and buffalo mammary tissue derived primary cells were grown in Dulbecco's Modified Eagle's Medium (DMEM) supplemented with $10 \%$ heat-inactivated fetal bovine serum (FBS) and $1 \mathrm{X}$ penicillin/streptomycin antibiotics (100 units/ml penicillin and 100 $\mathrm{ug} / \mathrm{ml}$ streptomycin). H460 cell line was obtained from NCCS, Pune and HCT116 cell line was a kind gift from Dr. Bert Vogelstein. 
Citation: Baru A, Dogra N, Mukhopadhyay T (2016) Methyl N-(6-Phenylsulfanyl-1h-Benzimidazol-2-YI) Carbamate: A Non-Toxic Substitute of Colchicine for Quality Metaphase Chromosome Preparation from Normal and Tumor Cells for Cytogenetic Analysis. Biol Syst Open Access 5: 160. doi:10.4172/2329-6577.1000160

Page 2 of 5

\section{Cell viability assay}

Cells were seeded at a density of 5000 cells/well into 96 well plate and $24 \mathrm{~h}$ after seeding; cells were treated with different doses of FZ. Cell viability was measured by MTT assay.

\section{FACS analysis}

Cells were treated with $1 \mathrm{uM} \mathrm{FZ}$ or $0.02 \mathrm{uM}$ colchicine for the indicated time intervals. Cells were then washed with PBS, trypsinized and fixed in $70 \%$ ethanol overnight at $4^{\circ} \mathrm{C}$. The next day, cells were centrifuged at $1000 \mathrm{rpm}$ for $5 \mathrm{~min}$, the supernatant was carefully aspirated and the pellet was resuspended in PBS containing $40 \mathrm{ug} / \mathrm{ml}$ PI and $100 \mathrm{ug} / \mathrm{ml}$ RNase. FACS analysis was done on a BD FACS Array system.

\section{Determination of mitotic index}

H460 and buffalo primary cells growing on cover slips were exposed to $1 \mathrm{uM} \mathrm{FZ}$ or $0.02 \mathrm{uM}$ colchicine for $24 \mathrm{~h}$. After treatment, cells were fixed with freshly prepared $4 \%$ paraformaldehyde, washed with PBS and stained with DAPI at $100 \mathrm{ng} / \mathrm{ml}$ concentration for $15 \mathrm{~min}$. The cells were then washed once with pre-warmed PBS and examined under a fluorescence microscope. Cells from at least five different areas were counted and mitotic cells were scored.

\section{Whole blood culture}

Whole blood $(0.2 \mathrm{ml})$ was obtained from a healthy 30 year old female and cultured at $37^{\circ} \mathrm{C}$ for $72 \mathrm{~h}$ in $5 \mathrm{ml}$ RPMI1640 medium supplemented with $10 \%$ heat-inactivated fetal bovine serum (FBS), $1 \mathrm{X}$ penicillin/streptomycin antibiotics solution (100 units/ml penicillin and $100 \mathrm{ug} / \mathrm{ml}$ streptomycin) and $0.5 \%$ phytohaemagglutinin (PHA). Cultures were inspected every morning and evening for change in $\mathrm{pH}$ or infection and were shaken to break the clumps of RBCs.

\section{Chromosome preparation from PBLs}

Chromosome preparations were obtained using the standard technique. Around $3 \mathrm{~h}$ prior to harvesting the culture, cells in mitotic stage were arrested by adding colchicine or FZ at final concentrations of $0.02 \mathrm{uM}$ and $1 \mathrm{Um}$, respectively. Cultures were then transferred to centrifuge tubes and centrifuged at $1200 \mathrm{rpm}$ for $5 \mathrm{~min}$. Supernatants were removed, cells were resuspended in $10 \mathrm{ml}$ pre-warmed $0.56 \% \mathrm{KCl}$ and incubated at $37^{\circ} \mathrm{C}$ for $18-20 \mathrm{~min}$. Tubes were centrifuged at 1200 $\mathrm{rpm}$ for $5 \mathrm{~min}$ at room temperature, supernatants were discarded, pellets were gently vortexed and cells were fixed in $10 \mathrm{ml}$ acetomethanol (1:3) for $1 \mathrm{~h}$. Finally, cells were again centrifuged at 1000 $\mathrm{rpm}$ for $5 \mathrm{~min}$ at RT and cell pellets were thoroughly resuspended in $0.4 \mathrm{ml}$ of acetomethanol by gentle mixing. Few drops of cell suspensions were used to make metaphase plates on clean slides as per standard method. Cells were stained with Giemsa for 3-4 min and rinsed twice with tap water. Slides were mounted with DPX and examined for metaphase chromosome spreads under a Nikon bright field microscope at $100 \mathrm{X}$ magnification.

\section{Chromosome preparation from cell lines}

$24 \mathrm{~h}$ after seeding, cells were treated with colchicine $(0.02 \mu \mathrm{M})$ or FZ $(1 \mathrm{uM})$ for $4 \mathrm{~h}$ at $37^{\circ} \mathrm{C}$. Mitotic cells were shaken off and collected after treatment. Cells were centrifuged at $1000 \mathrm{rpm}$ for $5 \mathrm{~min}$ at room temperature. Supernatants were discarded and $1 \mathrm{ml}$ of hypotonic solution $(0.56 \% \mathrm{KCl})$ was added. The cell pellet was gently resuspended and incubated for $30 \mathrm{~min}$ at $37^{\circ} \mathrm{C}$. Next, the cells were briefly centrifuged $(1200 \mathrm{rpm})$ for $5 \mathrm{~min}$ and cell pellet was fixed in acetomethanol. 2-3 drops of the cell suspension were used to make metaphase plates on slides. Slides stained with Giemsa were air dried and mounted with DPX. Chromosomes were examined using a Nikon bright field light microscope at 100X magnification.

\section{Results}

\section{FZ induces metaphase arrest and inhibits cell growth}

H460 and A549 non-small cell lung cancer cell lines were plated onto 96 well plates $(5 \times 104$ cells/well). Next day, cells were exposed to different concentrations of FZ for $48 \mathrm{~h}$. MTT assay was performed to determine cell viability. A decrease in cell viability was observed with increasing dose of FZ treatment (Figure 1). Since it is known that FZ interferes with the tubulin of parasites, we examined the morphology of the cells after FZ treatment. When cells were stained with DAPI and examined under fluorescent microscope, a large number of mitotic cells were observed following FZ treatment. Previously it has been reported that FZ interacts specifically with parasite tubulin but its effect on mammalian tubulin is unknown. Therefore, we treated cells with FZ to examine if it was able to cause metaphase arrest. Cells were treated with $1 \mathrm{uM} \mathrm{FZ}$ and $20 \mathrm{nM}$ colchicine, which served as positive control, for $24 \mathrm{~h}$. Cells were then stained with DAPI and observed under fluorescence microscope. A number of mitotic cell were visible in both FZ and colchicine treatments. (Figure 2a) 200 cells from different fields were counted manually and the percent metaphase cell population was scored. Results showed that colchicine and FZ both induced mitotic arrest to a comparable level. 13\% mitotic arrest was observed with colchicine whereas FZ caused mitotic arrest of 18\% cells in $\mathrm{H} 460$ cell line. FZ induced mitotic arrest to a significantly higher level in primary cells $(\sim 36 \%)$ as compared to colchicine $(\sim 6 \%)$ (Figure 2b).

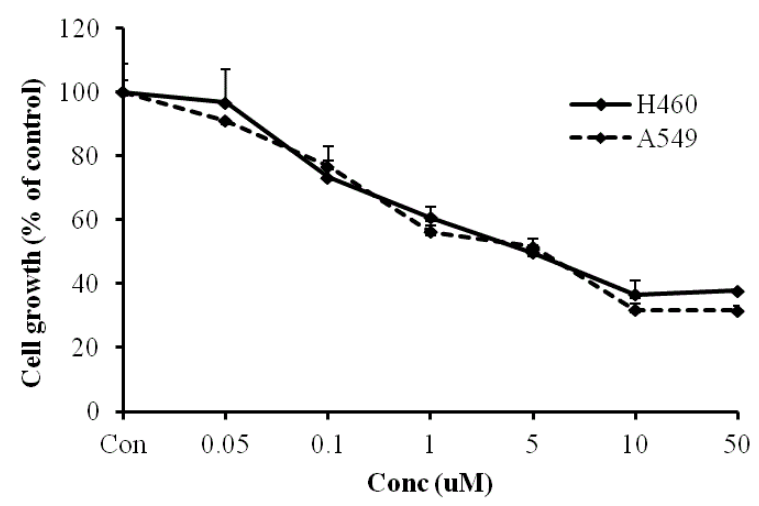

Figure 1: FZ inhibits proliferation of human non-small cell lung cancer cells - H460 and A549 cells were treated with FZ in a dose dependent manner for $48 \mathrm{~h}$ and MTT assay was done to determine the IC50 value of cell growth inhibition. IC50 value $(1 \mathrm{uM})$ was used for chromosome preparations. 
Citation: Baru A, Dogra N, Mukhopadhyay T (2016) Methyl N-(6-Phenylsulfanyl-1h-Benzimidazol-2-Yl) Carbamate: A Non-Toxic Substitute of Colchicine for Quality Metaphase Chromosome Preparation from Normal and Tumor Cells for Cytogenetic Analysis. Biol Syst Open Access 5: 160. doi:10.4172/2329-6577.1000160

Page 3 of 5

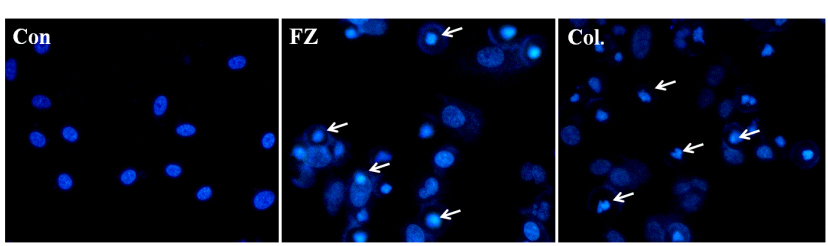

Figure 2a: FZ induced mitotic arrest in both tumor cell lines as well as primary cells in culture. a) Representative images of control, FZ and colchicine treated H460 cells stained with DAPI and examined under fluorescence microscope. (Arrowheads pointing mitotic cells).
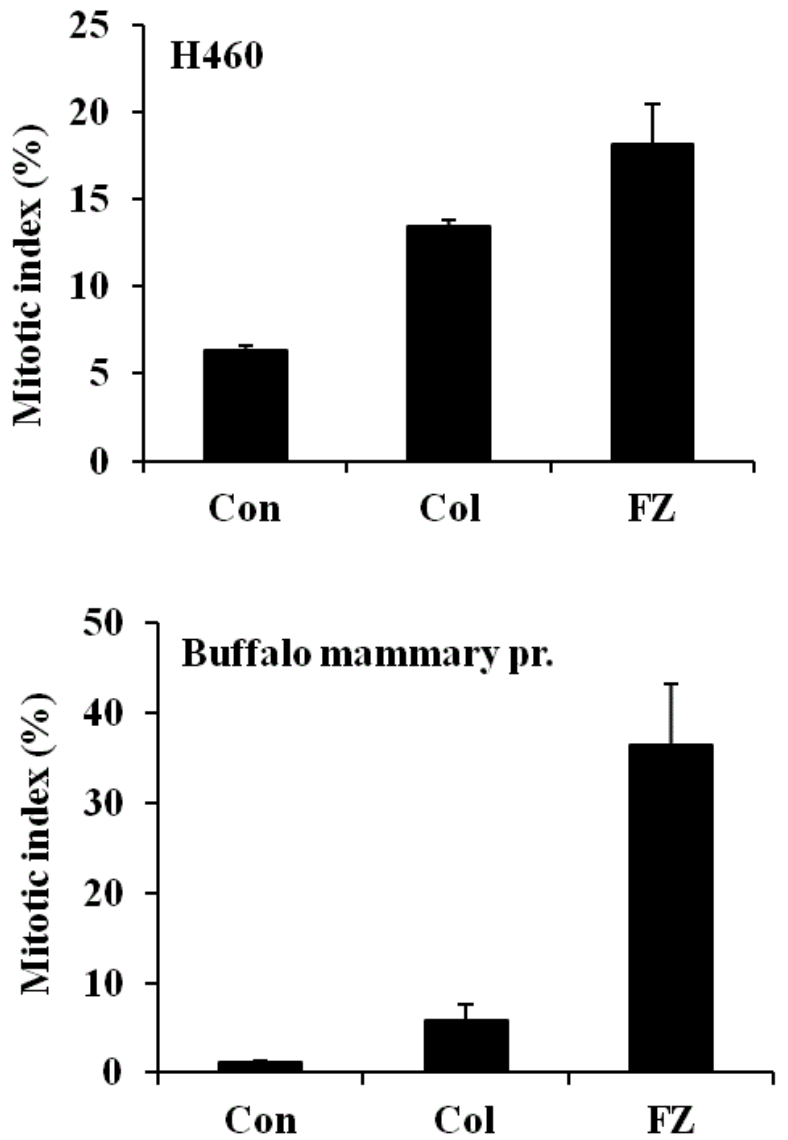

Figure 2b: FZ induced mitotic arrest in both tumor cell lines as well as primary cells in culture. b) $\mathrm{H} 460$ and buffalo primary cells were treated with FZ or colchicine for $24 \mathrm{~h}$, stained with DAPI and mitotic cells were counted manually from three different microscopic fields and compared.

\section{FZ induced cell cycle arrest comparable to colchicine}

Perturbation in the mitotic process results in G2/M phase arrest. In order to compare the effects of colchicine and FZ on cell cycle, H460 cells were exposed to $0.05 \mathrm{uM}$ colchicine or $1 \mathrm{uM} \mathrm{FZ}$ for $24 \mathrm{~h}$ and the cell cycle distribution was analyzed by flow cytometry. The results showed a significant increase in the G2/M population in FZ treated samples as compared to untreated control cells. The percentage of cells arrested in G2/M by both drugs was comparable ( 45\% G2/M by FZ and $\sim 49 \%$ by colchicine). Overall, our data suggests that these two drugs induce G2/M arrest to a similar extent in H460 cell line (Figure 3).

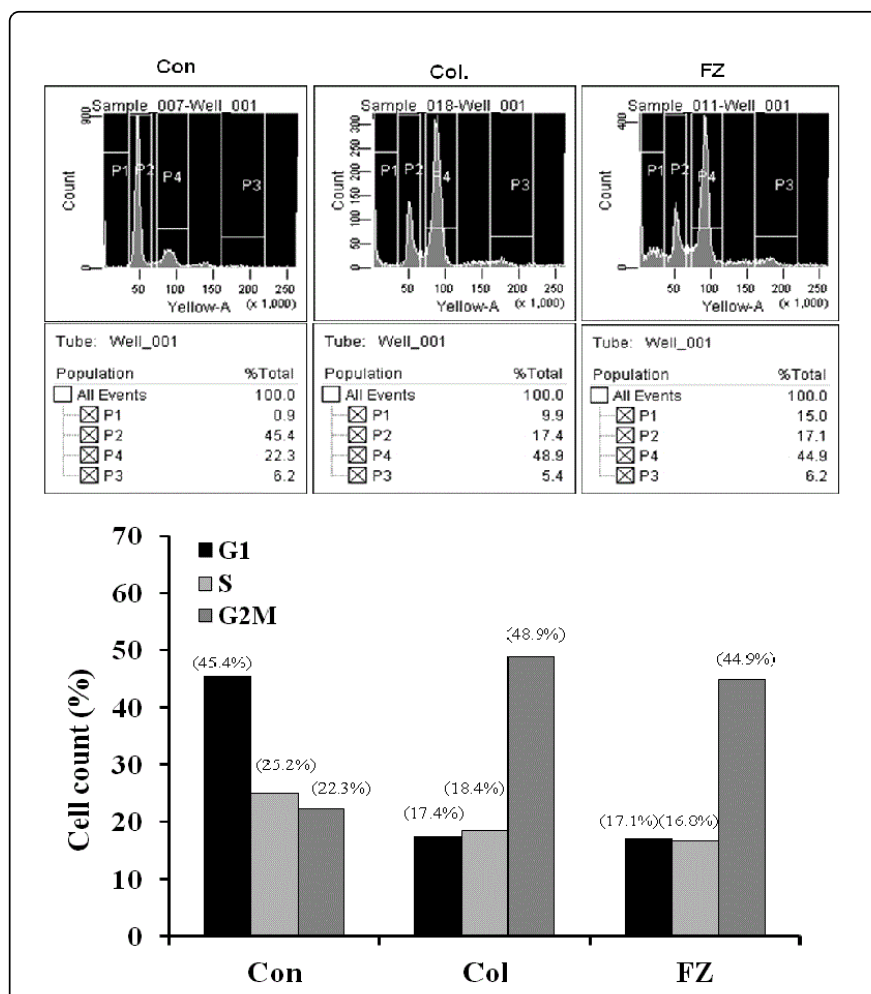

Figure 3: $\mathrm{FZ}$ induces $\mathrm{G} 2 / \mathrm{M}$ arrest - $\mathrm{H} 460$ cells were treated with colchicine or FZ for $24 \mathrm{~h}$ and cell cycle analysis was done by flow cytometry.

\section{FZ yields quality metaphase chromosome spreads}

Peripheral blood lymphocytes were cultured for $72 \mathrm{~h}$ as described under "Materials and Methods", following which the cells were divided into two sets and briefly treated with either $0.02 \mathrm{uM}$ colchicine or $1 \mathrm{uM}$ FZ for $3 \mathrm{~h}$. Both the treatments yielded metaphase plates having comparable mitotic indices (Figure 4). FZ treatment resulted in $\sim 12 \%$ metaphase cells. We next examined the effect of FZ on chromosome preparation from adherent cells. Human non-small cell lung cancer cell line $\mathrm{H} 460$ was grown in DMEM medium with $10 \%$ FBS and cells were exposed to colchicine or FZ as before and the mitotic cells were harvested for preparing chromosome plates as per Kohda et al. [11,12]. The chromosomes were stained with Geimsa and examined under microscope (Figure 4). FZ treatment was found to yield good quality and well spread chromosome plates, which is essential for various cytogenetic analyses. FZ treatment of both peripheral blood lymphocytes as well as adherent cell lines resulted in equally good metaphase plates comparable to colchicine treatment. We determined the chromosome spread yielding ability of FZ in cells from other species as well. Buffalo mammary primary cells growing in monolayer were used for this purpose. Results showed that FZ was also effective in 
Citation: Baru A, Dogra N, Mukhopadhyay T (2016) Methyl N-(6-Phenylsulfanyl-1h-Benzimidazol-2-Yl) Carbamate: A Non-Toxic Substitute of Colchicine for Quality Metaphase Chromosome Preparation from Normal and Tumor Cells for Cytogenetic Analysis. Biol Syst Open Access 5: 160. doi: 10.4172/2329-6577.1000160

Page 4 of 5

making metaphasic chromosome spreads from buffalo primary cell line as shown in Figure 4.

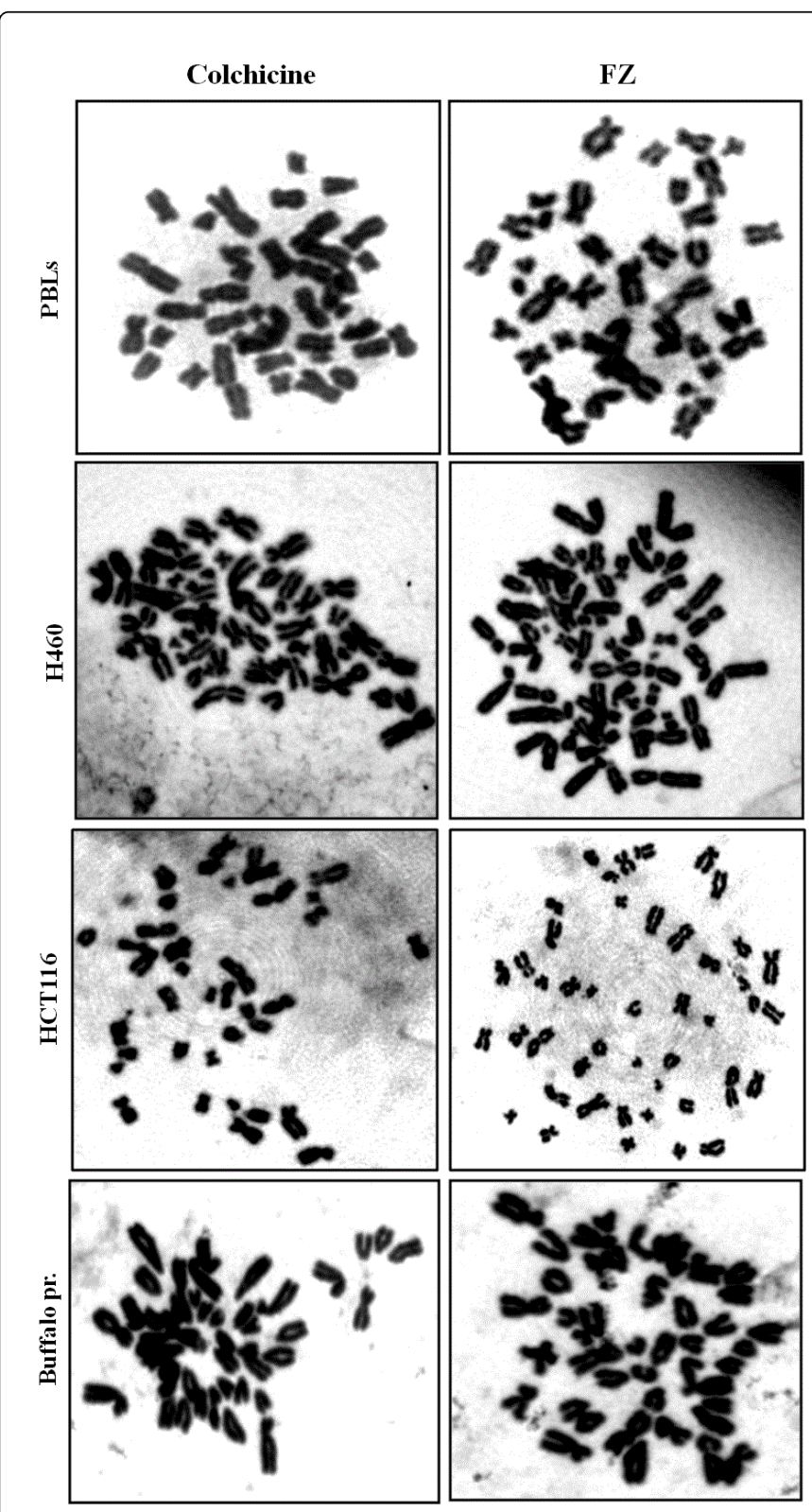

Figure 4: Metaphase chromosome preparation from different cells using FZ and colchicine - Metaphase chromosome plates prepared from peripheral blood culture, H460 human non-small cell lung cancer cell line, HCT116 cell line and buffalo mammary primary cells using $0.02 \mathrm{uM}$ colchicine and $1 \mathrm{uM}$ Fenbendazole. (Modal chromosome nos.: A549-66, H460-57, HCT116-45, Buffalo-50, PBL-46).

Altogether, our results demonstrate that $\mathrm{FZ}$ is a useful agent for preparation of chromosome spreads from peripheral blood lymphocytes, adherent cultured cells (H460 and HCT116) as well as buffalo primary cells. Chromosomes prepared from HCT116, a colorectal cancer cell line using FZ were processed for $\mathrm{G}$ banding. As expected, chromosomes spreads made by using FZ could be successfully processed for G-banding (data not shown).

\section{Discussion}

Colchicine, a well-known microtubule inhibitor, is widely used for the preparation of metaphase chromosomes particularly for routine analysis of G-banded chromosomes, as well as other molecular cytogenetic studies. Here we present evidence that FZ acts by interfering with the mitotic spindle leading to sustained mitotic arrest. Mitotic arrest caused by colchicine is often accompanied by aberrant chromosome condensation, particularly in tumor cells. A strong affinity of colchicine for tubulin binding involved in the deregulation of fundamental cellular processes in spindle dynamics results in metaphase arrest, however, duration of the colchicine treatment often has a profound consequence on structural organization of the chromosomes. As a result, colchicine does not always yield good chromosome preparations from tumor tissues. Our results show that $\mathrm{FZ}$, which is a much weaker microtubule inhibitor as compared to colchicine, yields high quality chromosome plates from both normal peripheral blood lymphocytes as well as from tumor cell lines and primary cultured cells. When compared, both colchicine and FZ yield large number of metaphase plates but the morphology of chromosomes prepared after FZ treatment were much better than that of colchicine. Our earlier studies revealed that FZ action could be reversed as opposed to colchicine treatment. FZ blocks the cells at G2/M phase and preferably works better with slow growing normal cells. The lower toxicity of FZ helps to accumulate large number of mitotic cells for routine cytogenetic and molecular cytogenetic analysis.

\section{Conclusion}

We report $\mathrm{FZ}$ as a novel inexpensive and relatively less toxic agent that can inhibit cell growth by arresting them at G2M phase of cell cycle and can be used as a suitable substitute for colchicine for preparation of good quality metaphase chromosome spreads from adherent or suspension cultures of both normal and cancer cells.

A.B. and N.D. carried out the molecular studies and drafted the manuscript. T.M. conceived the study and proofread the manuscript. All authors read and approved the final manuscript.

\section{References}

1. Serpinskaya AS, Gelfand VI, Kopnin BP (1981) Comparison of mitostatic effect, cell uptake and tubulin-binding activity on colchicine and colcemid. Biochim Biophys Acta 673: 86-92.

2. Tijo JHLA (1956) The chromosome number of man. Hereditas 42: 1-6.

3. Ireland CM, Gull K, Gutteridge WE, Pogson CI (1979) The interaction of benzimidazole carbamates with mammalian microtobule protein. Biochem Pharmacol 28: 2680-2682.

4. Lacey E (1990) Mode of action of benzimidazoles. Parasitol Today 6: 112-115.

5. Katiyar SK, Gordon VR, McLaughlin GL, Edlind TD (1994) Antiprotozoal activities of benzimidazoles and correlations with betatubulin sequence. Antimicrob Agents Chemother 38: 2086-2090.

6. Goshima G, Vale RD (2003) The roles of microtubule-based motor proteins in mitosis: Comprehensive RNAi analysis in the Drosophila S2 cell line. J Cell Biol 162: 1003-1016.

7. Gull K, Dawson PJ, Davis C, Byard EH (1987) Microtubules as target organelles for benzimidazole anthelmintic chemotherapy. Biochem Soc Trans 15: 59-60.

8. Laclette JP, Guerra G, Zetina C (1980) Inhibition of tubulin polymerization by mebendazole. Biochem Biophys Res Commun 92: $417-423$. 
Citation: Baru A, Dogra N, Mukhopadhyay T (2016) Methyl N-(6-Phenylsulfanyl-1h-Benzimidazol-2-YI) Carbamate: A Non-Toxic Substitute of Colchicine for Quality Metaphase Chromosome Preparation from Normal and Tumor Cells for Cytogenetic Analysis. Biol Syst Open Access 5: 160. doi:10.4172/2329-6577.1000160

Page 5 of 5

9. Villar D, Cray C, Zaias J, Altman NH (2007) Biologic effects of fenbendazole in rats and mice: a review. J Am Assoc Lab Anim Sci 46: 8-15.

10. Dogra N, Mukhopadhyay $T$ (2012) Impairment of the ubiquitinproteasome pathway by methyl N-(6-phenylsulfanyl-1H-benzimidazol-2yl)carbamate leads to a potent cytotoxic effect in tumor cells: A novel antiproliferative agent with a potential therapeutic implication. J Biol Chem 287: 30625-30640.
11. Kohda A, Taguchi H, Okumura K (2001) Preparation of extended metaphase chromosomes from human cultured cells using a topoisomerase II inhibitor, ICRF-193. Bioscience, Biotechnology and Biochemistry 65: 1248-1251.

12. Stevens JB (2007) Mitotic cell death by chromosome fragmentation. Cancer Res 67: 7686-7694. 